\title{
Role of follow-up imaging after resection of brain arteriovenous malformations in pediatric patients: a systematic review of the literature
}

\author{
Joaquin E. Jimenez, BS, Zachary C. Gersey, MS, Jason Wagner, BS, Brian Snelling, MD, \\ Sudheer Ambekar, MD, and Eric C. Peterson, MD \\ Department of Neurosurgery, University of Miami Miller School of Medicine, Miami, Florida
}

\begin{abstract}
OBJECTIVE Pediatric patients are at risk for the recurrence of brain arteriovenous malformation (AVM) after resection. While there is general consensus on the importance of follow-up after surgical removal of an AVM, there is a lack of consistency in the duration of that follow-up. The object of this systematic review was to examine the role of follow-up imaging in detecting AVM recurrence early and preventing AVM rupture.
\end{abstract}

METHODS This systematic review was performed using articles obtained through a search of the literature contained in the MeSH database, according to the Preferred Reporting Items for Systematic Reviews and Meta-Analyses (PRISMA) guidelines.

RESULTS Search results revealed 1052 articles, 13 of which described 31 cases of AVM recurrence meeting the criteria for inclusion in this study. Detection of AVM occurred significantly earlier (mean $\pm S D, 3.56 \pm 3.67$ years) in patients with follow-up imaging than in those without (mean $8.86 \pm 5.61$ years; $p=0.0169$ ). While $13.34 \%$ of patients who underwent follow-up imaging presented with rupture of a recurrent AVM, $57.14 \%$ of those without follow-up imaging presented with a ruptured recurrence $(p=0.0377)$.

CONCLUSIONS Follow-up imaging has an integral role after AVM resection and is sometimes not performed for a sufficient period, leading to delayed detection of recurrence and an increased likelihood of a ruptured recurrent AVM.

https://thejns.org/doi/abs/10.3171/2016.9.PEDS16235

KEY WORDS arteriovenous malformation; follow-up imaging; recurrence; pediatrics; vascular disorders

$\mathrm{C}$ EREBRAL arteriovenous malformations (AVMs) are rare congenital lesions formed from vascular dysgenesis of the capillary bed during the 3rd week of gestation. ${ }^{27,28}$ Approximately $15 \%$ of patients with AVMs are children, but these lesions cause $30 \%-50 \%$ of the intracranial hemorrhages in the pediatric population. ${ }^{8,10,12}$ Pediatric AVM patients are more likely to present with hemorrhage and have a higher annual bleeding risk than adults. ${ }^{13,15,16,18,20}$

Complete obliteration of the malformation through resection, endovascular embolization, stereotactic radiosurgery, or multimodal therapy is the goal of treatment and is confirmed by a negative cerebral angiogram after interven- tion. ${ }^{5}$ Although this "angiographic cure" was once thought to eliminate future risk, recent reports suggest both that completely resected AVMs in pediatric patients still recur and that pediatric patients have a higher recurrence rate after treatment compared with that in adults. ${ }^{2,3,7,11,14,24}$ Thus, long-term follow-up may be advisable.

Consensus on the duration of and the imaging modality used in follow-up, as well as the timing of and the factors contributing to recurrence, have yet to be established in pediatric AVM patients. In this review of the literature, we sought to ascertain the timing of recurrence and the appropriate follow-up management in pediatric AVM patients with angiographically proven obliteration. 
TABLE 1. Search term combinations

\begin{tabular}{ll}
\hline \multicolumn{1}{c}{ Set 1 } & \multicolumn{1}{c}{ Set 2 } \\
\hline Cerebral AND AVM & Surgery \\
\hline Intracranial AND AVM & Resection \\
\hline $\begin{array}{c}\text { Cerebral AND arteriovenous AND } \\
\text { malformation }\end{array}$ & Surgery AND follow-up \\
\hline $\begin{array}{l}\text { Intracranial AND arteriovenous AND } \\
\text { malformation }\end{array}$ & Resection AND follow-up \\
\hline
\end{tabular}

A total of 16 combinations of the search terms were used; every combination of terms from Set 1 was used with every combination in Set 2.

\section{Methods}

\section{Paper Selection}

A search of the literature was conducted using the $\mathrm{MeSH}$ database for articles containing phrases related to the resection of cerebral AVMs with follow-up. A total of 16 combinations of search terms were used (Table 1).
Studies were included for record screening if they had been published in English between January 1, 2000, and December 31, 2014, had been performed in humans, were available in full text, and were case reports, clinical trials, or randomized controlled trials. A list of nonredundant articles was then screened by title, abstract, and full text to compile a final list of papers that met inclusion criteria consisting of the following: patients younger than 18 years of age, AVMs treated using resection either with or without prior embolization or radiosurgery, and the paper discussed an instance of AVM recurrence. Articles describing patients with associated intracranial aneurysms were included, whereas those describing patients with any other associated intracranial pathology such as tumors or cavernous malformations were excluded. In the articles in which not all patients met the criteria for inclusion, data were collected for qualifying patients whenever possible; otherwise these papers were excluded. A secondary search was conducted using paper references and Google Scholar, and 11 papers were obtained from this search. All inclusion and exclusion criteria were set before the search was conducted, according to the Preferred Reporting Items

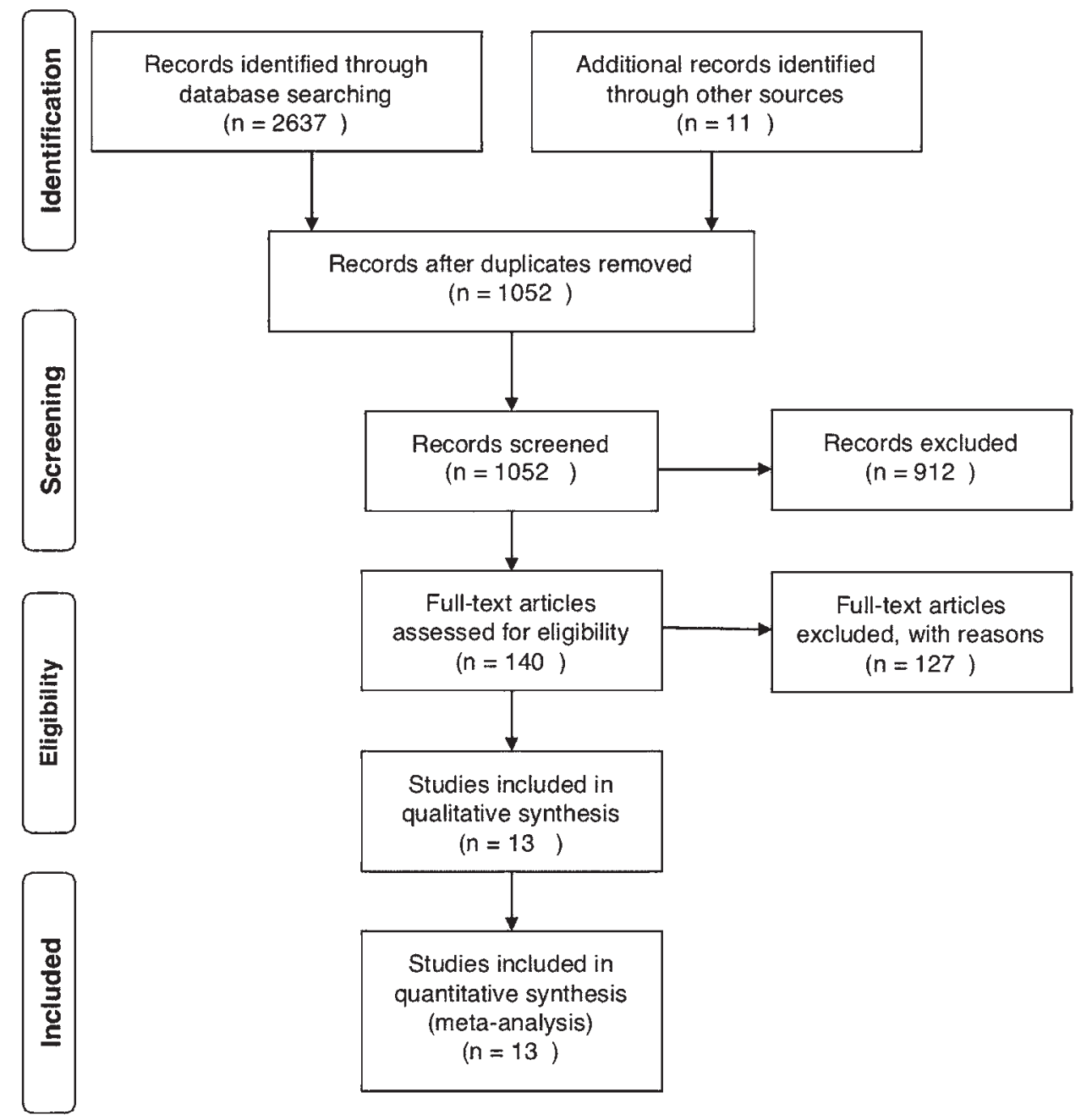

FIG. 1. Flowchart depicting study inclusion process according to PRISMA guidelines. 
TABLE 2. Initial AVM presentation

\begin{tabular}{|c|c|c|c|c|c|c|c|c|}
\hline Authors \& Year & $\begin{array}{l}\text { Patient } \\
\text { No. }\end{array}$ & $\begin{array}{c}\text { Sex/ } \\
\text { Age (yrs) }\end{array}$ & AVM Location & $\begin{array}{l}\text { SM } \\
\text { Grade }\end{array}$ & DVD & $\begin{array}{l}\text { AVM } \\
\text { Size }\end{array}$ & Presentation & Treatment \\
\hline Irie et al., 2000 & 1 & $\mathrm{~F} / 8$ & Brainstem & NR & Yes & NR & Diplopia, nystagmus, ataxia & Resection \\
\hline Akimoto et al., 2003 & 1 & $\mathrm{~F} / 10$ & Corpus callosum, occipital & NR & Yes & NR & $\mathrm{ICH}$ & Resection \\
\hline \multirow[t]{2}{*}{ Ali et al., 2003} & 1 & $\mathrm{M} / 7$ & Frontal & NR & NR & NR & $\mathrm{ICH}$ & Resection \\
\hline & 2 & $\mathrm{M} / 7$ & Parietal & NR & NR & NR & $\mathrm{ICH}$ & Resection \\
\hline \multirow[t]{2}{*}{ Andaluz et al., 2004} & 1 & $M / 4$ & Temporal & NR & Yes & $3-6 \mathrm{~cm}$ & $\mathrm{ICH}$ & Resection \\
\hline & 2 & $\mathrm{~F} / 6$ & Corpus callosum & NR & Yes & NR & $\mathrm{ICH}$ & Resection \\
\hline \multirow[t]{3}{*}{ Bristol et al., 2006} & 1 & NR/NR & Cerebellum & V & NR & NR & NR & Resection \\
\hline & 2 & NR/NR & Occipital & IV & NR & NR & NR & Resection \\
\hline & 3 & NR/NR & Parietal & III & NR & NR & NR & Resection \\
\hline \multirow[t]{6}{*}{ Klimo et al., 2007} & 1 & $\mathrm{M} / 11$ & Parietal & III & NR & NR & $\mathrm{ICH}$ & Resection \\
\hline & 2 & $\mathrm{M} / 12$ & Parietal & II & NR & NR & $\mathrm{ICH}$ & Resection \\
\hline & 3 & $\mathrm{~F} / 7$ & Interhemispheric & II & NR & NR & $\mathrm{ICH}$ & Resection \\
\hline & 4 & $\mathrm{~F} / 1$ & Temporal & III & NR & NR & Nystagmus & Resection \\
\hline & $5 a$ & $M / 9$ & Parietal & II & NR & NR & $\mathrm{ICH}$ & Resection \\
\hline & $5 b$ & $\mathrm{M} / 10$ & - & - & NR & NR & - & - \\
\hline \multirow[t]{4}{*}{ Maher \& Scott, 2009} & 1 & NR/NR & NR & NR & NR & NR & NR & NR \\
\hline & 2 & NR/NR & NR & NR & NR & NR & NR & NR \\
\hline & 3 & NR/NR & NR & NR & NR & NR & NR & NR \\
\hline & 4 & NR/NR & NR & NR & NR & NR & NR & NR \\
\hline Park \& Kwon, 2009 & 1 & $\mathrm{M} / 12$ & Frontal & NR & Yes & $3-6 \mathrm{~cm}$ & Incidental & Resection \\
\hline \multirow[t]{3}{*}{ Takagi et al., 2010} & 1 & $\mathrm{M} / 11$ & Insula & III & Yes & NR & $\mathrm{ICH}$ & Resection \\
\hline & 2 & $\mathrm{~F} / 6$ & Insula & III & Yes & NR & $\mathrm{ICH}$ & Resection \\
\hline & 3 & $\mathrm{~F} / 4$ & Parietal & II & Yes & NR & Seizures & Resection \\
\hline Weil et al., 2011 & 1 & $\mathrm{~F} / 8$ & Occipital & III & No & $3-6 \mathrm{~cm}$ & $\mathrm{ICH}$ & Resection \\
\hline McCarthy et al., 2012 & 1 & $\mathrm{~F} / 6$ & Frontal & II & Yes & $3-6 \mathrm{~cm}$ & $\mathrm{ICH}$ & Embolization \& resection \\
\hline \multirow[t]{6}{*}{ Morgan et al., 2012} & 1 & $\mathrm{~F} / 17$ & Parieto-occipital & III & Yes & $3-6 \mathrm{~cm}$ & Seizures & Resection \\
\hline & 2 & $\mathrm{M} / 12$ & Corpus callosum & II & Yes & $<3 \mathrm{~cm}$ & $\mathrm{ICH}$ & Resection \\
\hline & 3 & $\mathrm{M} / 7$ & Cingulate & III & No & $3-6 \mathrm{~cm}$ & $\mathrm{ICH}$ & Resection \\
\hline & $4 a$ & $\mathrm{M} / 17$ & Midbrain & III & Yes & $<3 \mathrm{~cm}$ & $\mathrm{ICH}$ & Resection \\
\hline & $4 b$ & $\mathrm{M} / 17$ & - & - & - & - & - & - \\
\hline & 5 & $\mathrm{M} / 5$ & Frontal & IV & Yes & $3-6 \mathrm{~cm}$ & $\mathrm{ICH}$ & Resection \\
\hline $\begin{array}{l}\text { Blauwblomme et al., } \\
2014\end{array}$ & 1 & NR/NR & NR & NR & NR & NR & NR & Resection \\
\hline
\end{tabular}

$\mathrm{DVD}=$ deep venous drainage; $\mathrm{ICH}=$ intracranial hemorrhage; $\mathrm{NR}=$ not reported; $-=$ data for a second consecutive recurrence.

for Systematic Reviews and Meta-Analyses (PRISMA) guidelines (Fig. 1).

\section{Data Collection and Analysis}

Collected data included article title, year of publication, names of authors, number of patients, patient sex, patient age at initial AVM diagnosis, location of initial AVM, mode of presentation, Spetzler-Martin (SM) grade, AVM size, deep venous drainage, treatment modality, angiographic confirmation of complete AVM obliteration, duration of follow-up, follow-up modality, follow-up findings, number of recurrences, recurrence presentation, time between initial resection and detection or presentation of recurrence, and whether recurrent AVM was located in the resection site or a new location.
Percentages were calculated based on all patients for whom the specific parameter was available (not all papers listed every parameter discussed). Follow-up status was assessed according to whether patients were actively undergoing periodic follow-up imaging at the time of the recurrence. A comparison of survival curves was conducted using the log-rank test to compare recurrence curves for patients with and without follow-up imaging. A nonparametric Wilcoxon rank-sum test was used in comparing the time until recurrence detection based on whether patients were undergoing follow-up. Fisher's exact test was used to determine if there was a difference in the rates of hemorrhage of the recurrent AVM in patients with or without imaging follow-up. Statistical tests were performed in SAS University Edition (SAS Institute Inc.) 
TABLE 3. Follow-up and AVM recurrence

\begin{tabular}{|c|c|c|c|c|c|c|}
\hline Authors \& Year & $\begin{array}{l}\text { Patient } \\
\text { No. }\end{array}$ & $\begin{array}{l}\text { Time From Resection } \\
\text { to Recurrence (yrs) }\end{array}$ & Follow-Up & $\begin{array}{l}\text { Imaging } \\
\text { Modality }\end{array}$ & $\begin{array}{c}\text { Site of } \\
\text { Recurrence }\end{array}$ & Presentation \\
\hline Irie et al., 2000 & 1 & 10 & Imaging & DSA & Same & Asymptomatic \\
\hline Akimoto et al., 2003 & 1 & 17 & None & None & New location & $\mathrm{ICH}$ \\
\hline \multirow[t]{2}{*}{ Ali et al., 2003} & 1 & 8 & None & None & Same & $\mathrm{ICH}$ \\
\hline & 2 & 8 & None & None & Same & $\mathrm{ICH}$ \\
\hline \multirow[t]{2}{*}{ Andaluz et al., 2004} & 1 & 5 & None & None & Same & Headache \\
\hline & 2 & 3 & Imaging & MRI & Same & Asymptomatic \\
\hline \multirow[t]{3}{*}{ Bristol et al., 2006} & 1 & 5 & NR & NR & NR & NR \\
\hline & 2 & 3 & NR & NR & NR & NR \\
\hline & 3 & 2 & Imaging & MRI & NR & Asymptomatic \\
\hline \multirow[t]{6}{*}{ Klimo et al., 2007} & 1 & 0.5833 & Imaging & DSA & Same & Asymptomatic \\
\hline & 2 & 6 & None & None & Same & Seizures \\
\hline & 3 & 0.5833 & Imaging & DSA & Same & Asymptomatic \\
\hline & 4 & 2 & None & None & New location & $\mathrm{ICH}$ \\
\hline & $5 a$ & 0.5 & Imaging & DSA & NR & Asymptomatic \\
\hline & $5 b$ & 6 & NR & NR & NR & NR \\
\hline \multirow[t]{4}{*}{ Maher \& Scott, 2009} & 1 & 1 & Imaging & MRI & NR & Asymptomatic \\
\hline & 2 & 1 & Imaging & MRI & NR & Asymptomatic \\
\hline & 3 & 3 & Imaging & MRI & NR & Asymptomatic \\
\hline & 4 & 11 & Imaging & MRI & NR & Asymptomatic \\
\hline Park \& Kwon, 2009 & 1 & 1 & Imaging & DSA & Same & Asymptomatic \\
\hline \multirow[t]{3}{*}{ Takagi et al., 2010} & 1 & 0.25 & Imaging & DSA & Same & Asymptomatic \\
\hline & 2 & 0.25 & Imaging & DSA & Same & Asymptomatic \\
\hline & 3 & 0.25 & Imaging & DSA & Same & Asymptomatic \\
\hline Weil et al., 2011 & 1 & 16 & None & None & Same & $\begin{array}{l}\text { Headache, nau- } \\
\text { sea, dizziness }\end{array}$ \\
\hline McCarthy et al., 2012 & 1 & 9 & Imaging & CTA & Same & Asymptomatic \\
\hline \multirow[t]{6}{*}{ Morgan et al., 2012} & 1 & 3.75 & Imaging & DSA & NR & Asymptomatic \\
\hline & 2 & 7.833 & Imaging & DSA & NR & $\mathrm{ICH}$ \\
\hline & 3 & 7.083 & Imaging & DSA & NR & Asymptomatic \\
\hline & $4 a$ & 1.25 & Imaging & DSA & NR & $\mathrm{ICH}$ \\
\hline & $4 b$ & 5 & Imaging & DSA & NR & $\mathrm{ICH}$ \\
\hline & 5 & 1 & Imaging & DSA & NR & Asymptomatic \\
\hline Blauwblomme et al., 2014 & 1 & 9 & Imaging & MRI + DSA & NR & Asymptomatic \\
\hline
\end{tabular}

$\mathrm{CTA}=\mathrm{CT}$ angiography.

and GraphPad Prism version 6.0e (GraphPad Software Inc.).

\section{Results}

\section{Patient Demographics and AVM Characteristics}

Thirty patients from 13 papers were included in this review (Tables 2 and 3). ${ }^{1-3,6,7,17,19,22-24,26,29,30}$ Mean patient age at initial presentation of AVM was 8.92 years (range 1-17 years). All patients experienced AVM recurrence, and 2 patients experienced 2 recurrences each (total of 32 recurrences). There were 12 male $(54.55 \%)$ and $10 \mathrm{fe}-$ male $(45.45 \%)$ patients; sex was unspecified for 8 patients. Of the 30 patients, $17(77.27 \%)$ originally presented with AVM rupture and 5 (22.73\%) without (2 with seizures; 1 with nystagmus; 1 with nystagmus, diplopia, and ataxia; and 1 with incidentally discovered AVM); this parameter was unreported in 8 cases. None of the initial AVMs were classified as SM Grade I, 6 (33.33\%) were Grade II, 9 (50\%) were Grade III, 2 (11.11\%) were Grade IV, 1 (5.56\%) was Grade V (12 unreported). Size of the initial AVM was largely unreported (21 cases). Two (22.22\%) of the AVMs were less than $3 \mathrm{~cm}$ in diameter and 7 (77.78\%) were between 3 and $6 \mathrm{~cm}$. The majority of initial AVMs were supratentorial (22 cases [88\%]), 3 (12\%) were infratentorial, and 5 were unspecified. Among the initial AVMs, $2(13.33 \%)$ contained only superficial venous drainage, while 13 (86.67\%) contained deep drainage; drainage was unspecified in 15 cases. All initial AVMs in this review were treated with resection. One $(3.85 \%)$ was treated with 

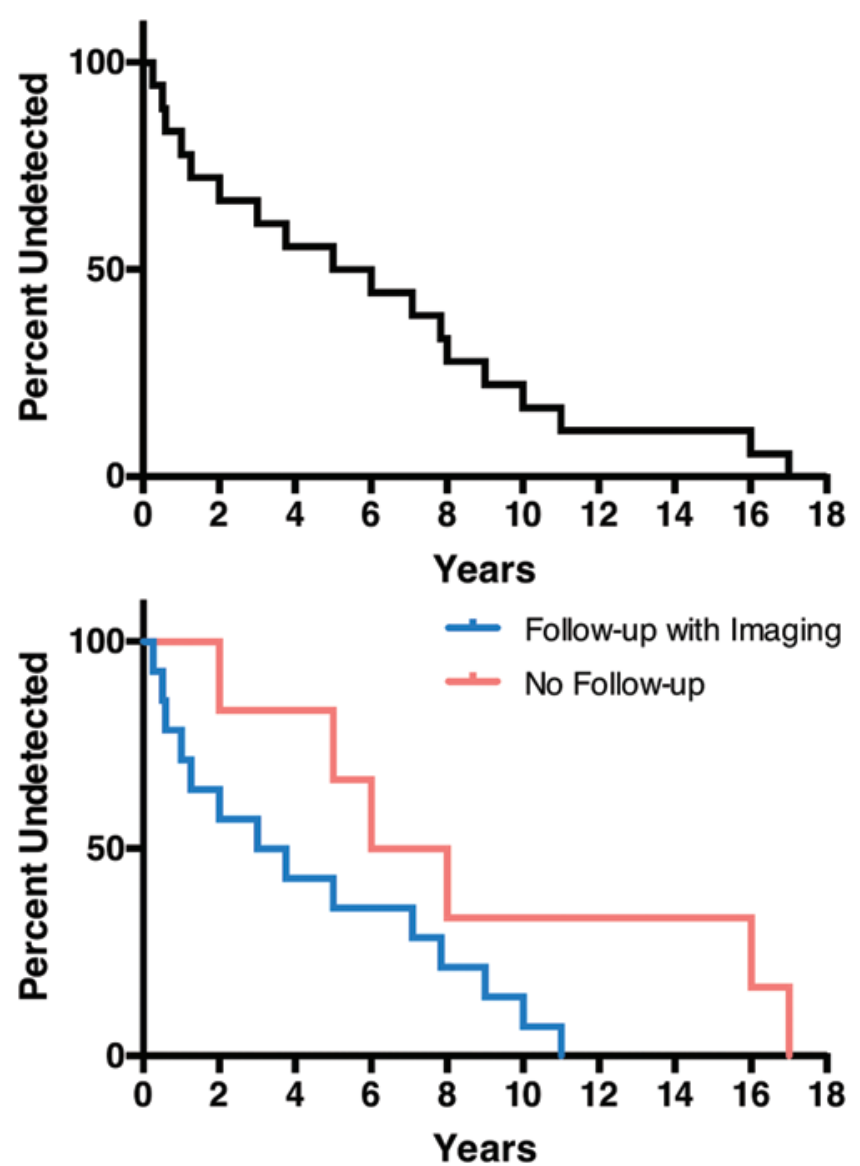

FIG. 2. Upper: Plot displaying the distribution of time until AVM recurrence in the selected patient population. No recurrences were reported after 17 years. Lower: Recurrence curves differed significantly based on follow-up status $(p<0.05)$. Figure is available in color online only.

embolization prior to resection, and $25(96.15 \%)$ received no prior treatment before resection (4 unreported). None were treated with stereotactic radiosurgery prior to resection.

\section{Follow-Up and Recurrence Detection}

All recurrent AVMs were documented after initial postoperative angiography had demonstrated complete obliteration of the original lesion (angiographic cure). Recurrent AVMs resected in the pediatric patients occurred across a highly varied range of time (Fig. 2 upper). The earliest recurrences were detected at 3 months postresection, whereas the latest recurrences were detected at 17 years postresection. Overall, the average time to recurrence was $4.82 \pm 4.49$ years (mean $\pm \mathrm{SD}$ ). All documented recurrences were detected either by imaging on follow-up or by clinical presentation of the AVM after the follow-up had expired. Among all AVM recurrences, 22 (68.75\%) occurred while the patients were still undergoing periodic follow-up imaging, whereas $7(21.88 \%)$ occurred in patients beyond the periodic follow-up. The follow-up status for 3 recurrences $(9.38 \%$ ) was not described; thus, these cases were not used in subsequent analyses.

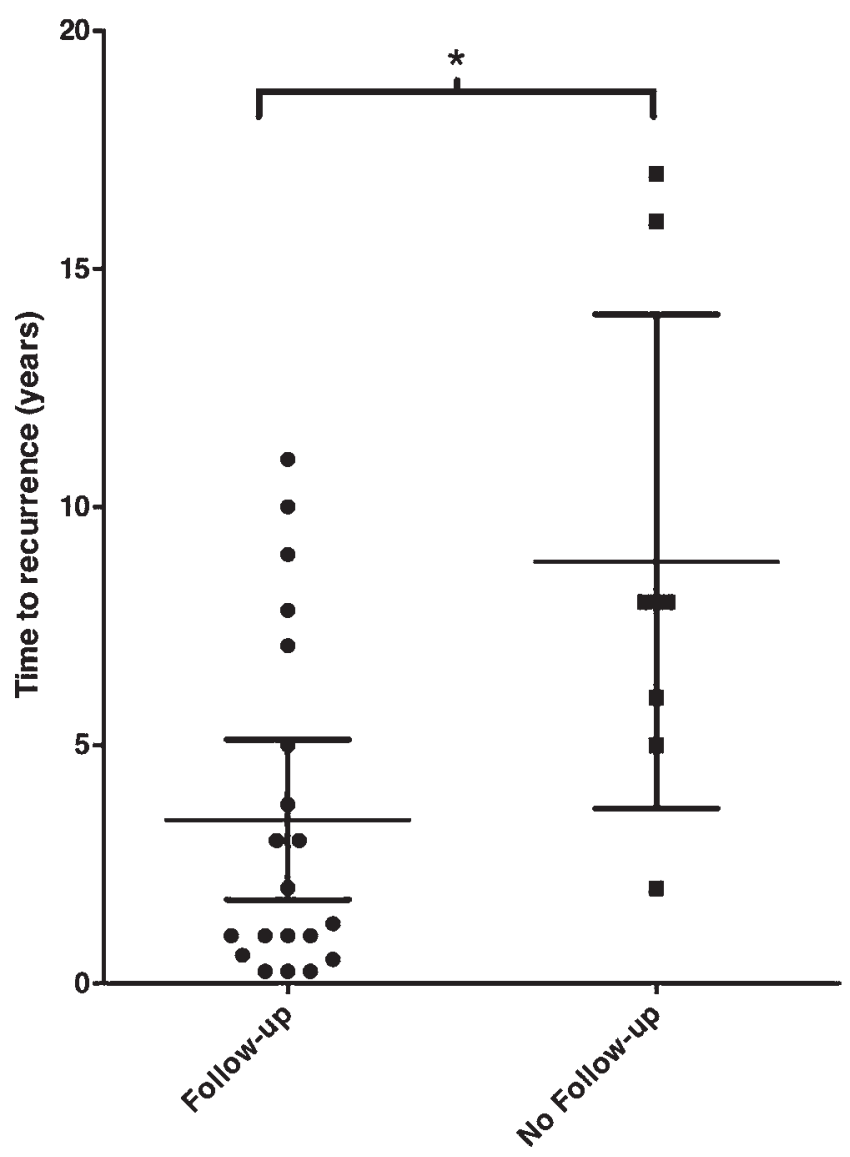

FIG. 3. Graph comparing time to recurrence in patients with and without follow-up imaging. Patients with follow-up imaging had earlier recurrence detection ( $\left.{ }^{*} p<0.05\right)$. Each dot and each square represent a patient.

Recurrence curves were significantly different between patients undergoing follow-up imaging and those who were not (HR 2.112, 95\% CI 1.319-4.561, $\mathrm{p}=0.0122$; Fig. 2 lower). Recurrences were detected earlier in the patients with follow-up imaging than in those without $(\mathrm{p}=$ 0.0169; Fig. 3). The average time to recurrence detection in patients with postoperative follow-up was $3.56 \pm 3.67$ years (median 1.65 years). The average time to recurrence in those without follow-up imaging was $8.86 \pm 5.61$ years (median 8 years). Patients without follow-up imaging had $\mathrm{AVM}$ recurrence detection as late as 17 years postresection, whereas those with follow-up imaging presented with recurrence no later than 11 years postresection.

Patients without follow-up imaging had a far greater risk of presenting with AVM rupture than those with follow-up imaging (RR 4.1905, 95\% CI 1.22-14.36, p $=0.0377$ ). Only $3(13.34 \%)$ of the 22 AVM recurrences in patients with follow-up imaging were detected with AVM rupture and hemorrhage (Fig. 4). Among the patients without follow-up imaging, 4 (57.14\%) of 7 recurrences presented with AVM rupture and hemorrhage and $3(42.86 \%)$ unruptured AVM recurrences were detected symptomatically (for example, seizures, focal neurological deficits). In the patients with follow-up imaging, all 


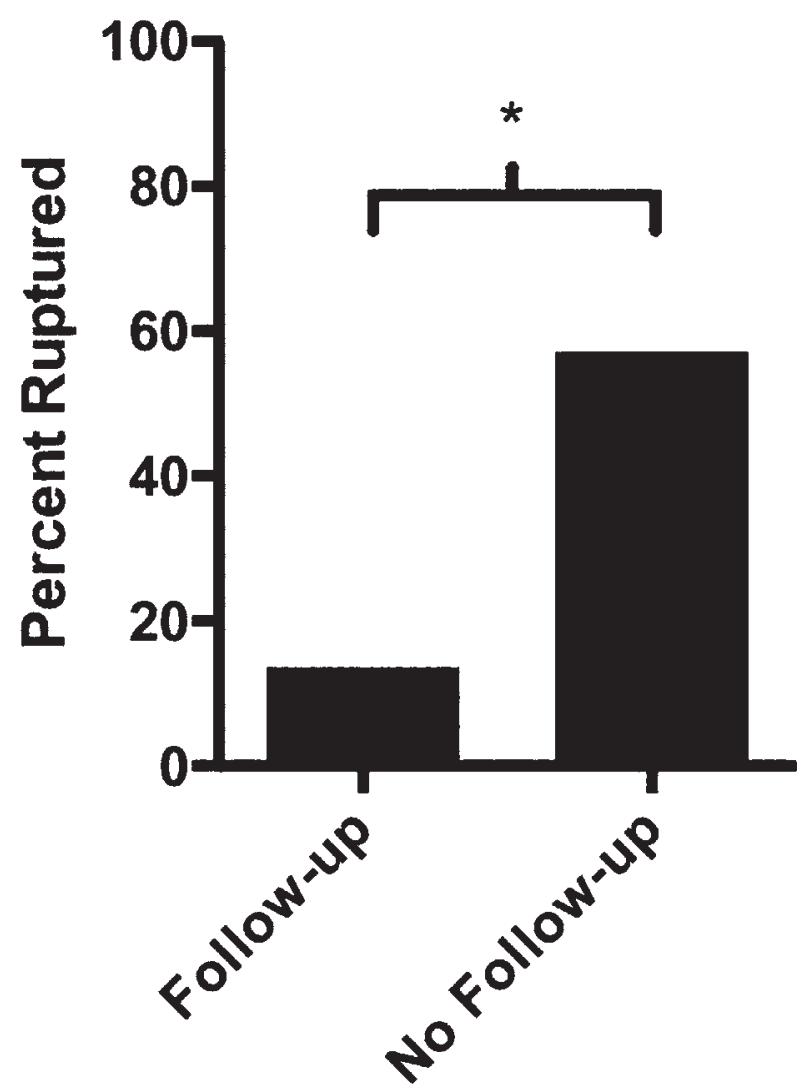

FIG. 4. Bar graph comparing the proportion of ruptured recurrent AVMs in patients with or without follow-up imaging. Of those patients without follow-up imaging, $57.14 \%$ presented with rupture, whereas $13.34 \%$ of those with follow-up imaging experienced recurrent AVM rupture $\left({ }^{*} p<0.05\right)$.

unruptured AVM recurrences were detected asymptomatically.

\section{Discussion}

The primary finding of this report is that even in angiographically cured AVMs, extended imaging follow-up leads to earlier detection of recurrence and lowers the rate of rupture. While follow-up imaging of cerebral AVMs is widely advocated and often performed, there is little clarity regarding the standard duration of that follow-up. While adults more commonly present with AVMs, pediatric patients have a greater risk of recurrence., ${ }^{2,7}$ Thus, understanding the role of follow-up imaging in pediatric patients is crucial.

The question of when it is appropriate to discontinue follow-up does not have a clear answer. The latest case of AVM recurrence we found occurred 17 years postresection in a patient who was not undergoing follow-up imaging. ${ }^{1}$ It is difficult to know when late-presenting recurrences developed in patients who were not undergoing follow-up imaging since it may have been many years between the time that the recurrence developed and when it manifested clinically. No recurrences were reported past 11 years postresection among the patients undergoing follow-up imaging. One study examining the natural history of AVM demonstrated a hemorrhage risk of $4.61 \%$ per year, sup- porting the view that AVMs can remain asymptomatic for a prolonged period. ${ }^{9}$ It is unclear if recurrent AVMs are more prone to earlier rupture, however.

Here we have demonstrated that recurrence screening with imaging modalities has a significant effect on outcomes after recurrence. We have also quantified the magnitude of that effect. However, decisions about recurrence screening guidelines must take into account the prevalence of recurrence and the cost-effectiveness and risks of screening. Consequently, it is impossible to establish definitive recurrence screening guidelines on the basis of this work alone. Previous follow-up duration recommendations of less than 10 years may be inadequate for detecting some AVM recurrences in the pediatric population..$^{21,22,30}$ Future studies should use our results combined with the other variables mentioned in determining follow-up guidelines. In the absence of such guidelines, we believe pediatric patients should be offered follow-up imaging until the age of 18 years.

No imaging modality stood out as superior in our sample of AVM recurrences. However, Morgenstern et al. showed that digital subtraction angiography (DSA) is more sensitive than MRI in detecting AVM recurrence and recommended DSA at 1,3 , and 5 years postresection and every 5 years thereafter. ${ }^{25}$ Other groups have reported cases in which MRI may have missed subtle AVM recurrences. ${ }^{5}$ While DSA may be more sensitive in detecting AVM recurrence, ${ }^{1,5,21}$ MRI has successfully detected asymptomatic recurrences in several documented cases in which results suggestive of AVM recurrence were often followed up with DSA. 3,6,7,22 While some data indicate that DSA may be preferable, MRI can be used as an alternative if patients or parents refuse follow-up with DSA. Few studies have directly compared these 2 imaging modalities. Therefore, selecting the follow-up imaging modality should involve discussions with patients regarding the evidence for and the risks of the different modalities.

There is a general lack of consistency in the reporting of AVM-associated variables, such as size, location, SM grade, deep venous drainage, details on how total resection was confirmed, and so forth. Additionally, many studies fail to report the follow-up frequency, which is crucial for minimizing radiation exposure on follow-up while continuing to prevent recurrent AVM rupture. For these reasons, it is important that investigators report supplemental de-identified individual patient data for AVMs in a standardized model, similar to that proposed by Atkinson et al. ${ }^{4}$

Unfortunately, data on these parameters were often unavailable for many of the included patients so that sample sizes were too small to determine if they had a real effect on the timeframe of recurrence development. For example, the presence of deep venous drainage was readily ascertainable for only half of the 30 patients included in the study, and initial SM grade was ascertainable for only 18 of the 30 patients. Other studies have associated the risk of recurrence with some parameters such as deep venous drainage. ${ }^{7}$ It would be interesting to see if AVM characteristics such as deep drainage also modify the time to recurrence. Future studies could look for associations between patient and AVM characteristics and the time to 
recurrence and perhaps use their findings to help guide decisions about follow-up duration and frequency.

Because our study involved the study of objective clinical parameters from patients documented in other studies and did not depend on the conclusions or statistical analysis in those studies, there is a lower risk of sources of bias in those studies affecting our results. Besides the standards set by our inclusion and exclusion criteria, we did not perform additional bias assessment.

Limitations at the review level include the limited availability of data on several parameters, making it impossible to ask questions about different AVM characteristics influencing the time to recurrence. Such data would have allowed for modification of follow-up guidelines based on initial AVM characteristics. At the outcome level, one limitation is that few data are available in terms of followup frequency, which could have an effect.

\section{Conclusions}

Recurrence constitutes an important risk after resection of brain AVMs in children. There is substantial variability in the current standards of AVM resection follow-up. Here we demonstrate that many patients are not followed up sufficiently, leading to delayed detection of recurrence and a greater likelihood of patients presenting with rupture of an AVM recurrence. Long-term angiographic followup after AVM resection is crucial in detecting recurrence and preventing rupture with its associated morbidity and mortality.

\section{Acknowledgments}

We thank Kaming Lo, MPH, Department of Public Health Sciences, Division of Biostatistics, University of Miami Miller School of Medicine, for his review of the statistical methods used in this study.

\section{References}

1. Akimoto H, Komatsu K, Kubota Y: Symptomatic de novo arteriovenous malformation appearing 17 years after the resection of two other arteriovenous malformations in childhood: case report. Neurosurgery 52:228-232, 2003

2. Ali MJ, Bendok BR, Rosenblatt S, Rose JE, Getch CC, Batjer $\mathrm{HH}$ : Recurrence of pediatric cerebral arteriovenous malformations after angiographically documented resection. Pediatr Neurosurg 39:32-38, 2003

3. Andaluz N, Myseros JS, Sathi S, Crone KR, Tew JM Jr: Recurrence of cerebral arteriovenous malformations in children: report of two cases and review of the literature. Surg Neurol 62:324-331, 2004

4. Atkinson RP, Awad IA, Batjer HH, Dowd CF, Furlan A, Giannotta SL, et al: Reporting terminology for brain arteriovenous malformation clinical and radiographic features for use in clinical trials. Stroke 32:1430-1442, 2001

5. Bendok BR, El Tecle NE, El Ahmadieh TY, Koht A, Gallagher TA, Carroll TJ, et al: Advances and innovations in brain arteriovenous malformation surgery. Neurosurgery 74 (Suppl 1):S60-S73, 2014

6. Blauwblomme T, Bourgeois M, Meyer P, Puget S, Di Rocco F, Boddaert N, et al: Long-term outcome of 106 consecutive pediatric ruptured brain arteriovenous malformations after combined treatment. Stroke 45:1664-1671, 2014

7. Bristol RE, Albuquerque FC, Spetzler RF, Rekate HL, McDougall CG, Zabramski JM: Surgical management of arte- riovenous malformations in children. J Neurosurg 105 (2 Suppl):88-93, 2006

8. Celli P, Ferrante L, Palma L, Cavedon G: Cerebral arteriovenous malformations in children. Clinical features and outcome of treatment in children and in adults. Surg Neurol 22:43-49, 1984

9. da Costa L, Wallace MC, ter Brugge KG, O’Kelly C, Willinsky RA, Tymianski M: The natural history and predictive features of hemorrhage from brain arteriovenous malformations. Stroke 40:100-105, 2009

10. D'Aliberti G, Talamonti G, Versari PP, Todaro C, Bizzozero L, Arena O, et al: Comparison of pediatric and adult cerebral arteriovenous malformations. J Neurosurg Sci 41:331-336, 1997

11. Freudenstein D, Duffner F, Ernemann U, Rachinger J, Grote E: Recurrence of a cerebral arteriovenous malformation after surgical excision. Cerebrovasc Dis 11:59-64, 2001

12. Gold AP, Challenor YB, Gilles FH, Hilal SP, Leviton A, Rollins EI, et al: Report of the Joint Committee for Stroke Facilities. IX. Strokes in children. 2. Stroke 4:1007-1052, 1973

13. Hashimoto N, Nozaki K: Do cerebral arteriovenous malformations recur after angiographically confirmed total extirpation? Crit Rev Neurosurg 9:141-146, 1999

14. Hino A, Fujimoto M, Iwamoto Y, Takahashi Y, Katsumori T: An adult case of recurrent arteriovenous malformation after "complete" surgical excision: a case report. Surg Neurol 52:156-159, 1999

15. Hladky JP, Lejeune JP, Blond S, Pruvo JP, Dhellemmes P: Cerebral arteriovenous malformations in children: report on 62 cases. Childs Nerv Syst 10:328-333, 1994

16. Hoh BL, Ogilvy CS, Butler WE, Loeffler JS, Putman CM, Chapman PH: Multimodality treatment of nongalenic arteriovenous malformations in pediatric patients. Neurosurgery 47:346-358, 2000

17. Irie K, Nagao S, Honma Y, Kunishio K, Ogawa T, Kawai N: Treatment of arteriovenous malformation of the brain-preliminary experience. J Clin Neurosci 7 (Suppl 1):24-29, 2000

18. Kader A, Goodrich JT, Sonstein WJ, Stein BM, Carmel PW, Michelsen WJ: Recurrent cerebral arteriovenous malformations after negative postoperative angiograms. J Neurosurg 85:14-18, 1996

19. Klimo P Jr, Rao G, Brockmeyer D: Pediatric arteriovenous malformations: a 15-year experience with an emphasis on residual and recurrent lesions. Childs Nerv Syst 23:31-37, 2007

20. Kondziolka D, Humphreys RP, Hoffman HJ, Hendrick EB, Drake JM: Arteriovenous malformations of the brain in children: a forty year experience. Can J Neurol Sci 19:40-45, 1992

21. Lang SS, Beslow LA, Bailey RL, Vossough A, Ekstrom J, Heuer GG, et al: Follow-up imaging to detect recurrence of surgically treated pediatric arteriovenous malformations. J Neurosurg Pediatr 9:497-504, 2012

22. Maher CO, Scott RM: Linear vein-based arteriovenous malformations in children. J Neurosurg Pediatr 4:12-16, 2009

23. McCarthy C, Kaliaperumal C, O'Sullivan M: Recurrence of a paediatric arteriovenous malformation 9 years postcomplete excision: case report and review of literature. BMJ Case Rep 2012:9-12, 2012

24. Morgan MK, Patel NJ, Simons M, Ritson EA, Heller GZ: Influence of the combination of patient age and deep venous drainage on brain arteriovenous malformation recurrence after surgery. J Neurosurg 117:934-941, 2012

25. Morgenstern PF, Hoffman CE, Kocharian G, Singh R, Stieg PE, Souweidane MM: Postoperative imaging for detection of recurrent arteriovenous malformations in children. J Neurosurg Pediatr 17:134-140, 2016

26. Park YS, Kwon JT: Recurrent cerebral arteriovenous malfor- 
mation in a child: case report and review of the literature. $\mathbf{J}$ Korean Neurosurg Soc 45:401-404, 2009

27. Ramey WL, Martirosyan NL, Zabramski JM, Spetzler RF, Kalani MY: A hierarchical model for the development of cerebral arteriovenous malformations. Clin Neurol Neurosurg 126:126-129, 2014

28. Stapf C, Mast H, Sciacca RR, Berenstein A, Nelson PK, Gobin YP, et al: The New York Islands AVM Study: design, study progress, and initial results. Stroke 34:e29-e33, 2003

29. Takagi Y, Kikuta K, Nozaki K, Hashimoto N: Early regrowth of juvenile cerebral arteriovenous malformations: report of 3 cases and immunohistochemical analysis. World Neurosurg 73:100-107, 2010

30. Weil AG, Li S, Zhao JZ: Recurrence of a cerebral arteriovenous malformation following complete surgical resection: a case report and review of the literature. Surg Neurol Int 2:175, 2011

\section{Disclosures}

The authors report no conflict of interest concerning the materi- als or methods used in this study or the findings specified in this paper.

\section{Author Contributions}

Conception and design: all authors. Acquisition of data: Jimenez, Gersey, Wagner. Analysis and interpretation of data: Jimenez, Gersey, Wagner. Drafting the article: Jimenez, Gersey, Wagner. Critically revising the article: all authors. Reviewed submitted version of manuscript: all authors. Approved the final version of the manuscript on behalf of all authors: Peterson. Statistical analysis: Jimenez, Gersey, Wagner. Administrative/technical/ material support: Jimenez, Gersey. Study supervision: Peterson, Snelling.

\section{Correspondence}

Eric C. Peterson, Department of Neurological Surgery, University of Miami Miller School of Medicine, Lois Pope LIFE Center, 2nd Fl., 1095 NW 14th Terrace, Miami, FL 33136. email: ericpete@ med.miami.edu. 